\title{
AUTHENTIC LEADERSHIP AND PERFORMANCE: THE MEDIATING ROLE OF EMPLOYEES' AFFECTIVE COMMITMENT
}

\author{
Neuza Ribeiro \\ neuza.ribeiro@ipleiria.pt \\ Management for Sustainability Research Center \\ School of Technology and Management \\ Polytechnic Institute of Leiria Campus 2 \\ Morro do Lena - Alto do Vieiro, 2411 - 901 Leiria - Portugal
}

\section{Daniel Roque Gomes \\ drmgomes@esec.pt}

CIC-Digital - Center for Research in Communication, Information and Digital Culture

School of Education (ESEC-IPC)

Polytechnic Institute of Coimbra,

Praça Herois do Ultramar, 3030-329 Coimbra, Portugal

\author{
Shaji Kurian \\ shaj_kurian@yahoo.com \\ Associate Professor (HR \& OB) \\ IFIM Business School, \\ \# 8P \& 9P, KIADB Industrial Area \\ Electronic City $1^{\text {st }}$ Phase \\ Bangalore 560100
}

To cite this document:

Neuza Ribeiro, Daniel Gomes, Shaji Kurian, (2018) "Authentic leadership and performance: the mediating role of employees' affective commitment", Social Responsibility Journal, Vol. 14 Issue: 1, pp.213-225, https://doi.org/10.1108/SRJ-06-2017-0111

Permanent link to this document:

https://doi.org/10.1108/SRJ-06-2017-0111 


\begin{abstract}
Purpose - This study aims to examine the relationship between authentic leadership (AL), affective commitment and individual performance. More specifically, this study aims to understand how (a) AL influences employees' affective commitment, (b) AL influences individual performance, (c) Affective commitment influences individual performance and (d) Affective commitment mediates the relationship between AL and Individual Performance.
\end{abstract}

Design/methodology/approach - Two hundred and twelve Portuguese employees participated in this study. A quantitative methodology was used. Baron and Kenny's linear regression method and Sobel test were used to test the mediation relationship.

Findings - The results reveal that affective commitment mediates the relationship between AL and employees' performance. In others words, leaders' authenticity promotes employees' affective commitment which, in turn, increases their individual performance.

Practical implications - This research has practical implications for human resources management in organizations, particularly in selection processes and training of leaders and managers. Practitioners looking to increase employee commitment and performance can do so by augmenting the AL.

Originality/value - This study enriches the knowledge about the relevance of emerging area such as AL theory and responds to the need to understand underlying mechanisms linking AL with workers' commitment and performance (i.e., testing the construct's nomological network).

Keywords Authentic Leadership, Affective Commitment, Individual Performance, Mediation

Paper type Research paper 


\section{Introduction}

Ever increasing corporate scandals associated with unscrupulous leaders of once-reputed companies suggests the relevance of new positive forms of leadership such as Authentic Leadership (AL), which is based on the moral character of the leader, concern for others, and congruency between ethical values and actions (Shahid, 2010). Avolio and Gardner (2005) have argued that leader's integrity is especially important in a turbulent work environment because authentic leaders must offer stability by promoting clear directions and values for followers to identify with. Followers' and organizations' effectiveness must be promoted via authentic leadership behaviors that also help to restore trust in leaders and organizations (Avolio and Mhatre, 2012; George, 2003). Walumbwa et al. (2008) argued that AL refers to a pattern of leadership behavior that promotes positive psychological competencies and a positive ethical climate in the workplace.

Previous research indicates that AL is related to several positive attitudes and behaviors, such as creativity, organizational citizenship behaviors, affective commitment, work engagement, job satisfaction, job performance, job resourcefulness (e.g., Avolio et al., 2004; Giallonardo et al., 2010; Rego et al., 2012; Rego et al.,2013; Semedo et al., 2016; Walumbwa et al., 2010). Ilies et al. (2005) also suggested that leaders with a relational authenticity will strive for an open and truthful relationships with their followers and such orientation will have positive outcomes. This study follows the same line of research, as it shows how perceptions of AL have impact on employees attitudes (affective commitment), and how this attitude impact their individual performance.

Empirical evidence on the relation between AL and follower work attitudes and behaviors is still scarce due to the novelty of the construct. Likewise, there are many studies on leadership and its consequences, but research regarding $\mathrm{AL}$ and its impact on employee attitudes and behavior is scarcely researched. Hence, this study aims to fill the research gap by demonstrating how the AL can be a real asset for employees' outcomes. Other researches also have tested the role of organizational commitment as a mediating variable on relationships between leadership behavior and job satisfaction/performance (Youssef, 2000) and work motivation and job performance (Trivellas, 2011). However, there is a lack of studies that specifically examined the role of affective commitment (organizational commitment dimension that has the most positive consequences on job performance and 
job satisfaction) as a variable mediating the relationship between AL and individual performance in Portuguese context.

More specifically this study aims to understand how (a) AL influences employees' affective commitment, (b) AL influences individual performance, (c) Affective commitment influences individual performance and (d) Affective commitment mediates the relationship between AL and Individual Performance.

This research may prove beneficial to managers and leaders by providing insights regarding the impact that AL has on employees' affective commitment, and examining how these factors potentially increase the individual performance. In Portugal, the recession of 2007 caused a probable slowdown in the level of affective commitment. It was very demanding for employees to be upbeat, positive, and optimistic in a crisis context. Many Portuguese workers have experienced, reduced wages and benefits during this period. To overcome this challenges, an extra effort with an effective leadership approach as well as an authentic leadership style found to have inspired employees. The findings of this study contribute to this emerging leadership literature by providing a comprehensive theoretical framework, which can explain the relationships among the AL, affective commitment and individual performance in a crisis setting.

\section{Research Background and Hypothesis Development}

Authentic Leadership

Although the concept of authenticity had been around since Aristotle (Harter, 2002), AL started receiving attention among researchers in the last decade (Clapp-Smith, Vogelgesang and Avey, 2009). AL is based on the moral character of the leader, concern for others, and congruency between ethical values and actions (Shahid, 2010). The most widely mentioned conceptualization of AL is stated by Walumbwa and colleagues (2008, p. 94) as "a pattern of leader behavior that draws upon and promotes both positive psychological capacities and a positive ethical climate, to foster greater self-awareness, an internalized moral perspective, balanced processing of information, and relational 
transparency on the part of leaders working with followers, fostering positive selfdevelopment". The process of AL combines the positive capacities of the leader in a highly developed organizational context (Luthans and Avolio, 2003).

The literature reveals that most academic researchers in the past have considered four dimensions of AL: (1) Self-awareness represents the degree to which the leader understand his/her strengths and weaknesses and the multifaceted nature of self and how others see him/her, and how (s)he impacts or influences others (Avolio, 2005; Walumbwa et al., 2008); (2) Relational Transparency refers to presenting the leaders' authentic self, their true feelings, and thoughts to followers (Avolio et al., 2004; Shamir and Eilam, 2005); (3) Balanced Processing refers to the degree to which the leader objectively analyzes all relevant information before making a decision and solicits views that challenge deeply-held positions (Gardner et al., 2005; Walumbwa et al., 2008); (4) Internalized Moral Perspective refers to the degree to which the leader is guided by internal moral standards and values, and results in behaviors and decisions consistent with these internalized values, to the detriment of group pressures, organizations or society pressures (Avolio and Gardner, 2005; Gardner et al., 2005; Walumbwa et al., 2008). Empirical and theoretical evidence suggests that a core AL factor can be extracted from the relationships among the four dimensions (Gardner et al., 2005; Kernis and Goldman, 2005; Rego et al., 2012; Walumbwa et al., 2008).

Literatures have identified several differences between AL theory and transformational (Joo and Nimon, 2014), charismatic, servant and spiritual leadership theories (Avolio and Gardner, 2005). Although some overlap exists between AL and these leadership theories, AL has unique components. AL have been posited to form a root construct (Avolio and Gardner, 2005) or a "key ingredient" (Simons, 1999) underlying other positive forms of leadership and its development (Avolio and Mhatre, 2012; Nazari and Emani, 2012).

Researchers have suggested that AL predicts several positive attitudes and behaviors such as psychological capital, creativity, organizational citizenship behaviors, work engagement, job resourcefulness, affective commitment and good performance (Avolio et al., 2004; Rego et al., 2013; Semedo et al., 2016; Walumbwa et al., 2010). Therefore, this study aims to respond to the suggestions of researchers (e.g., George et al., 2007), 
that $\mathrm{AL}$ is a good way to achieve lasting and positive results through its ability to improve affective commitment and individual performance.

\section{Authentic Leadership predicting Affective Commitment}

Affective Commitment (AC) is an attachment characterized by an identification to and involvement with the organization (Allen and Meyer, 2000). Together with normative and continuance commitment, $\mathrm{AC}$ is one component of the organizational commitment construct. The literatures reveal that out of three components of organizational commitment, the affective dimension has more desirable implications for the individual's behavior in the organization. AC is possibly the most studied component of organizational commitment (Meyer et al., 2002; Riketta, 2002).

Earlier researches have explored to determine the antecedents and effects of AC (e.g., Meyer et al., 2002; Rego et al., 2013) and have suggested that affectively committed individuals tend to perform their jobs better and be more productive (Meyer and Herscovitch, 2001; Meyer et al., 2002; Riketta, 2002). Steffens et al. (2014) found that leaders are able to encourage work engagement and prevent strain among group members by creating a mutual special sense of "us." These findings suggest that AL means being capable of enabling the development of a special sense of "us" shared among the leader and followers. It is possible that the higher degree of AL as perceived by employees, the stronger the emotional bond that unites them.

$\mathrm{AL}$ has been demonstrated to drive follower $\mathrm{AC}$ through trust in the leader and identification with the leader (Walumbwa et al. 2008, 2010, 2011). In other words, by being relationally transparent, behaving honestly and adopting a balanced information processing, authentic leaders develop affective attachment among followers in the workplace. Authentic leaders establish higher quality exchanges with the employees (LMX theory) because they constantly make efforts that incorporate moral principles in their behavior, values and beliefs, and employees reciprocating with greater AC.

Thus, AL is related to follower's AC (Leroy et al., 2012). Empirical evidence (Avolio et al., 2004; Leroy et al., 2012; Rego et al, 2013; Walumbwa et al., 2008) supports such a prediction and in view of these considerations, the following hypothesis is proposed: 
Hypothesis 1: Perceptions of AL will be positively related with employees AC.

\section{Authentic Leadership predicting Individual Performance}

In times of a crisis (Avolio and Mhatre, 2012; George, 2003) have argued that AL is important for developing confidence in leaders and promoting "pragmatic outcomes" (Cameron et al., 2004, p. 5). Employees' Individual Performance (IP) refers to a set of individual behaviors or actions that are relevant to the organization's goals (Campbell, 1990). The literature on AL has also found that leader's integrity drives follower performance (Leroy et al., 2012). Clapp-Smith et al. (2009) found AL to be positively related to employee performance.

AL has demonstrated to drive follower performance and organizational citizenship behaviors through enhanced trust in the leader and identification with the leader (Walumbwa et al. 2008, 2010, 2011). That is, followers' effectiveness must be supported by AL behaviors that also help to renovate trust in leaders and in/within organizations (Avolio and Mhatre, 2012; George, 2003). Thus, AL promotes positive attitudes and behaviors of employees and contributes to IP.

Authentic leaders objectively analyze all the relevant information before coming to a decision, seek the followers' inputs for decision making, and ask for views that may challenge deeply-held positions (Walumbwa et al., 2008, 2011). They also openly share that information with followers, and use it to strengthen them (Gardner et al., 2005). As consequences, employees become more confident in their abilities, employees' selfefficacy improves and they tend to perform their work better. Authentic leaders also focus on followers' talents and strengths, liberate their potential (Luthans and Avolio, 2003), and as a result, followers reciprocating with greater IP.

Thus, the following hypothesis is proposed:

Hypothesis 2: Employee perceptions of AL will be positively related with employees' IP. 
Workers' AC has been related with performance and organizational citizenship behaviors (Vandenabeele, 2009; Meyer et al. 2002). AC leads to improve in-role and extra-role performance (Allen and Meyer, 1996; Jaramillo et al., 2005; Riketta, 2002; Vandenberghe et al., 2004). Researchers found that affectively committed employees tend to perform their jobs better and be more productive (Meyer and Herscovitch, 2001; Meyer et al., 2002; Riketta, 2002).

In opposite to other types of organizational commitment (i.e., continuance commitment and normative commitment), individuals who experience $\mathrm{AC}$, pursue work-related goals more rigorously because AC may reflect follower's intrinsic work motivation (Meyer et al., 2004).

Rego and Souto (2004) argued that affectively-committed employees are more willing and motivated to contribute significantly towards the organization than employees who are less affectively-committed. Employees with high AC identify more with the notion of organizational success and are more committed to contributing to that success, and they tend to perform their work better. According to Meyer and Herscovitch (2001), a strong AC can increase the likelihood of the adoption of behaviors that are beneficial to the intended goal. Some authors propose that more affectively committed employees are more likely to perform better in their job functions (e.g., Meyer et al., 2002; Leroy et al., 2012).

In view of these considerations, the following hypothesis is proposed:

Hypothesis 3: AC will be positively related with IP.

Affective Commitment Mediating the Relationship between AL and Individual Performance

Avolio et al. (2004) suggested that authentic leaders are able to enhance follower work attitudes such as commitment, which in turn leads to higher levels of extra-effort and job performance. Gagné and Deci (2005) observed that follower's intrinsic work motivation 
may be especially important in driving the in-role and extra-role behaviors and thereby improving IP.

Authentic leaders stimulate positive emotions and a sense of identification among employees (Avolio et al., 2004). This process enables employees to bond with the leaders' values, beliefs and goals and therefore result in higher AC, and consequently, higher IP (Leroy et al., 2012).

In addition, by being relationally transparent, behaving honestly, and adopting a balanced processing of information, authentic leaders act as role models, stimulating trust and integrity within the organization (Walumbwa et al., 2011), and the employees reciprocate with higher AC (Bishop et al., 2005; Dayan, 2010). Committed employees tend to be more productive (Meyer and Herscovitch, 2001; Meyer et al., 2002; Leroy et al., 2012). Therefore, we argue that affective organizational commitment mediates the relationship between leader integrity and work role performance. Thus, the following hypothesis is proposed:

Hypothesis 4: AC mediates the relationship between AL and IP.

\section{Method}

\subsection{Sample and procedures}

This study sample consisted of 212 Portuguese workers. Using convenience sampling method, data was gathered from the central region of Portugal especially from small and medium sized companies, via an online survey design. No individual company provided more than $10 \%$ of responses. Participants were on an average 45.4 years old $(\mathrm{SD}=7.5)$, and $30,2 \%$ of the respondents were male. Regarding tenure, participants on an average had been employed in the organization for 21.4 years ( $\mathrm{SD}=9.4$ years).

As an option for enriching our data analysis procedures, we have performed bootstrapping technique (Efron, 1979) by permitting data analysis enhancements and calculating "the statistic of interest in multiple re-samples of the data set, and by sampling $n$ units with replacement from the original sample of $n$ units" (Preacher et al., 2007, p.190). The 
benefits of using bootstrapping in correlational studies have been well recognised (e.g., Shrout and Bolger, 2002) especially while assessing meditational effects similar to the ones that are foreseen in this study's model of analysis. In what regards the present study, we believe that the bootstrapping adds accuracy to our statistical results.

Regarding the procedure, a survey was developed to collect the data, informing the aims of the study, and assuring the anonymity and confidentiality of the participants' responses. To build the survey, we have fulfilled certain criteria to control for the impact of potential systematic errors (Podsakoff et al., 2003), notably to control errors derived from the items' characteristics and the context which the items were made available to the respondents the following steps were adopted: (a) the total respondents were guaranteed anonymity and confidentiality of information collected, and were told that there was no right or wrong answers; (b) there was randomness in the ordering of multiple items; (c) we did not use scales with bipolar numerical values or assign verbal designations for the midpoints of the scales.

\subsection{Measures}

\section{Authentic Leadership}

Perceptions of AL were measured by the 16 items of the Authentic Leadership Questionnaire (ALQ) (Copyright (C) 2007 ALQ by Bruce J. Avolio, William L. Gardner and Fred O. Walumbwa). Individuals reported the frequency (1: never, (...), 5: Often, if not always) with which their supervisors adopted the 16 behaviors/attitudes. Sample items include: (a) "Seeks feedback to improve interactions with others" (self-awareness); (b) "Says exactly what he or she means" (relational transparency); (c) "Demonstrates beliefs that are consistent with actions" (internalized moral perspective); (d) "Listens carefully to different points of view before coming to conclusions" (balanced processing). Cronbach's alpha was .96.

\section{Affective Commitment}

Four items adapted from Rego et al. (Rego and Cunha, 2008b; Rego et al., 2007) were used to measure AC. Sample items includeded statements such as: "I am proud to tell 
others that I am part of this organization" and "I feel like «part of the family» at my organization”. Using a seven-point Likert scale $(1=$ does not apply to me at all; $7=$ applies completely to me), participants were asked to indicate to what extent, each statement presented applied to them. Cronbach's alpha was .85 .

\section{Individual Performance}

Three items developed by Staples et al. (1999) and one item developed by Rego and Cunha (2008a) were used to access IP. Sample items included statements such as: "I am happy with the quality of my work output" and "My manager believes I am an efficient worker". Using a seven-point Likert scale $(1=$ does not apply to me at all; $7=$ applies completely to me), participants were asked to report the degree that each assertion applied to them. Cronbach's alpha was .63 which was higher than minimum value (.60) recommended by Hair et al. (1992).

\subsection{Common Method Variance}

The Harman test (1967) was performed in order to assure that the data do not account for significant amount of common method bias (Podsakoff et al., 2003). A principal component analysis (unrotated solution) of all the items revealed six factors with values above 1 . They accounted for $72,37 \%$ of the total variance, the first of which explained $34,36 \%$ of the variance, suggesting that the data was robust to common method variance.

\section{Findings}

Table I shows the correlation matrix of the study variables, the means, standard deviations, and the reliabilities. According to the correlation matrix, all variables of the model of analysis were positively and significantly associated with each other (AL-AC $(r$ $=.223 ; p<.01) / \mathrm{AL}-\mathrm{IP}(r=.195 ; p<.01) / \mathrm{IP}-\mathrm{AC}(r=.367 ; p<.01))$. It is noticed that age and IP were also positively and significantly associated with each other $(r=.170 ; p$ $<.05)$, and that gender had no association with any of the variables in the correlation matrix. 
[insert Table 1 here]

These results indicate to confirm our first, second and third hypotheses, foreseeing that AL is significantly and positively related with AC, and IP, as well as AC with IP. The study suggests that the authenticity of leaders is an important factor to promote employees' AC and IP.

In addition to these first results, our fourth hypothesis proposes a mediational effect of $\mathrm{AC}$ in the relation between AL and IP. To analyse this hypothesis, we have followed Baron and Kenny's (1986) linear regression method, and accordingly, three regression equations were tested: (first step) the predictor variable (AL) should affect the mediator variable (AC); (second step) the predictor variable should be affected by the dependent variable (IP); (third step) the mediator variable should affect the dependent variable. We have also made the option of selecting two control variables that seemed relevant in the context of this study as followed by Baron and Kenny's (1986) in their linear regression method: gender and age (this last one was important to control, as it presented significant association with the dependant variable). In addition to our data analysis procedures, we have also made the option of testing the mediational effect with Sobel Test (Sobel, 1982), by enabling a more direct estimation of indirect effects.

To develop our mediational analysis, we have made the option of controlling for the impact of gender and age in all our following statistical procedures. Following Baron and Kenny's procedure, regarding the predictor variable affecting the mediator variable (first step), it was possible to verify that $\mathrm{AL}$ and AC were positively related $(\beta=.192 ; p<.01$; $\left.R^{2 \text { Adjust. }}=.042\right)($ Table $2-$ Model 1: control variables/ Model 2: control variables and predictor). Then, we verified that AL and IP have also revealed significant relation (Table 3 - Model 1: control variables/ Model 2: control variables and predictor predictor: $\beta=$ $\left..188 ; p<.01 ; R 2^{\text {Adjust. }}=.063\right)$ (second step). For the third step (Table 3), we have verified that the relation between AL and IP becomes non-significant (Table 3, Model 3: $\beta=.122$; $p>.05$ ), and the effect of AC in IP was positive and significant (Table 3, Model 3: $\beta=$ $\left..339 ; p<.01 ; R 2^{\text {Adjust. }}=.161\right)$. Regarding Sobel Test's findings, study found the existence of mediation effect of AC in the relation between AL and IP $(Z=3.13299296 / p=.001)$. 
These results indicated a full mediation effect, and as such, supporting evidences for a validation of our fourth hypothesis.

[insert Table 2 here]

[insert Table 3 here]

[insert Figure 1 here]

\section{Analysis, Discussion, and Conclusions}

\subsection{Main Findings, Limitations, and Future Studies}

The results show that $\mathrm{AL}$ promotes $\mathrm{AC}$ which in turn, increases individual and organizational performance. This is consistent with other studies, which reported that perceptions of employees regarding their leaders' authenticity influence their emotional attachment to the team and organization (Avolio et al., 2004; Rego et al., 2013) and greater AC tend to influence their IP (Meyer and Herscovitch, 2001; Meyer et al., 2002).

Our results coincide with those of studies by Gardner et al. (2005), which suggest that employees are much more emotionally committed in the execution of their tasks and have a greater focus on achieving their objectives when their perceptions of their leaders' authenticity are strong (Darvish and Rezaei, 2011; Leroy et al., 2012). The employees' emotional bonds towards the organization influence their IP as other studies have shown (e.g. Meyer and Herscovitch, 2001; Meyer et al., 2002).

This study provides empirical evidence that the effect of employees' perception of their supervisors leadership style on their performance and emotional attachment to the organization. More specifically, the transparency in relationships and consistency between principles, words, and actions displayed by authentic leaders contributes to higher levels of AC and willingness to perform (Avolio et al., 2004).

Authentic leaders incorporate values, beliefs and moral principles, in their behavior, that influences the employee's AC (Alshammari et al., 2015), which in turn, increases their performance. This study reveals a full mediation of $\mathrm{AC}$ in the relationship between the perceptions of AL and IP. It suggests that perceptions of AL can stimulate employees' affective component to the organization, which in turn, promotes their IP. Other studies 
have also reached this conclusion showing that the authenticity of leaders is an important factor to awaken employees' AC (Leroy et al., 2012; Rego et al., 2013).

There are some limitations of the present study. The first limitation of this research is convenience sampling that is a sampling method used to choice a naturally occurring group within a population. Convenience samples often require less time and effort, thus are usually less costly. However, a convenience sampling method limits the generalizability of results, especially when we used online surveys because important respondents can be left out of the research. Second, same-source participants from our study rated the antecedent, mediating, and outcome variables in our study. Same-source data can be a possible limitation since they present the chance that these results can be attributed to common-method variance (Podsakoff et al., 2003). Some preventative measures were undertaken, such as the Harman test and other procedures described earlier to reduce or eliminate such variance. Nonetheless, future studies should collect the data at different points in time, or via a multiple-source method.

Our model showed a predictive ability of explaining individual performance in $16,1 \%$, implying that there are alternative variables able to increase the variance of individual performance, that were not considered in our model. It is plausible to consider that job demands, or job characteristics (for instance) would play a relevant role to explain individual performance as predictor variables. In addition, the study included only one mediating variable, but others are also plausible. For example, it is possible that authentic leaders develop hope, optimism, and resilience, which in turn, increases employees' performance. Future studies may include such variables as mediators.

\subsection{Theoretical Contributions}

Previous research called for empirical studies of AL across various contexts (Yammarino et al., 2008) and studies that measure the impact of AL on work attitudes (Leroy et al., 2012). Cooper et al. (2005) asserted the relevance of emerging area such as AL theory and emphasised that scholars need to give careful attention to identifying relevant construct outcomes (i.e., testing the construct's nomological network). Thus, this study was set out to address their suggestions and it tested the effect of AL on AC and IP and the mediating effect of AC on the relationship between AL and IP. 
In sum, the theoretical contribution of this study is that it extends the leadership literature by empirically testing the relationships among AL, AC and IP.

\subsection{Implications for management}

The results of this study have practical implications for human resources management in organizations, particularly in selection processes and training leaders and managers. Practitioners looking to increase employee commitment and performance can do so by augmenting the AL. Managers should seek to become more alert of their own moral weaknesses when pressured by external influences and also learn how to act consistent with their values. Managers should develop the 360 -feedback process that provides them with anonymous feedback from their superior, peers, and followers. By seeking out different opinions and visions, managers will be better informed in their decision making. Managers should not refuse information and show behavior that is inconsistent with their words. These behaviors tend to reduce trust. Increased levels of trust have been found to result to higher levels of growth and sustainable performance (Gatling et al., 2016). Finally, we also believe that organizations should develop strong internal communication programs seeking to stimulate internal cohesion and thus, supporting the role of the leaders in the way how they can maximize workers' contributions and skills.

\section{References:}

Allen, N. J. and Meyer, J. P. (2000), “Construct validation in organizational behavior research: The case of organizational commitment", in R. D. Goffin and E. Helmes (Eds.), Problems and solutions in human assessment, Norwell, MA, pp. 285-314.

Allen, N. J. and Meyer, J. P. (1996), “Affective, continuance, and normative commitment to the organization: An examination of construct validity". Journal of Vocational Behavior, Vol. 49, pp. 252-276.

Alshammari, A; Almutairi, N and Thuwaini, F. (2015), "Ethical Leadership: The Effect on Employees”. International Journal of Business and Management, Vol. 10 No.3, pp. 
108-116.

Avolio, B. J. and Gardner, W. L. (2005), “Authentic leadership development: Getting to the root of positive forms of leadership". The Leadership Quarterly, Vol. 16, pp. 315338.

Avolio, B. J. and Mhatre, K. H. (2012), “Advances in theory and research on authentic leadership". In K. S. Cameron and G. Spreitzer (Eds.), The Oxford Handbook of Positive Organizational Scholarship, Oxford University Press, Oxford, pp. 773-783.

Avolio, B., Gardner, W., Walumbwa, F.O, Luthans, F. and May, D.R. (2004), “Unlocking the mask: A look at the process by which authentic leaders impact follower attitudes and behaviors", The Leadership Quarterly, Vol. 15, pp. 801-823.

Avolio, B. (2005), Leadership development in balance: made/born, Lawrence Erlbaum, Mahwah.

Baron, R. M. and Kenny, D. A. (1986), “The moderator-mediator variable distinction in social psychological research: Conceptual, strategic, and statistical considerations", Journal of Personality and Social Psychology, Vol. 51, pp. 1173-1182.

Bishop, J. W., Scott, K. D., Goldsby, M. G., and Cropanzano, R. (2005), “A construct validity study of commitment and perceived support variables", Group \& Organization Management, Vol. 30 No. 2, pp. 153-180.

Cameron, K. S., Bright, D. and Caza, A. (2004), "Exploring the relationships between organizational virtuousness and performance", American Behavioral Scientist, Vol. 47 No. 6, pp. 1-24. 
Campbell, J. (1990), "Modeling the performance prediction problem in industrial and organizational psychology", in Dunnette, M. and Hough, L. (Eds) Handbook of organizational and industrial psychology, Consulting Psychologists Press, Palo Alto, CA, pp. 687-732.

Clapp-Smith, R., Vogelgesang, G. R. and Avey, J. B. (2009), “Authentic leadership and positive psychological capital: The mediating role of trust at the group level of analysis", Journal of Leadership and Organizational Studies, Vol. 15 No. 3, pp. 227-240.

Cooper, C. D., Scandura, T. A. and Schriesheim, C. A. (2005), "Looking forward but learning from our past: Potential challenges to developing authentic leadership theory and authentic leaders", Leadership Quarterly, Vol. 16, pp. 475-493.

Dayan, M. (2010), "Managerial trust and NPD team performance: Team commitment and longevity as mediators", Journal of Business \& Industrial Marketing, Vol. 25 No. 2, pp. 94-105.

Darvish, H. and Rezaei, F. (2011), "The impact of authentic leadership on job satisfaction and team commitment", Management \& Marketing Challenges for the Knowledge Society, Vol. 6 No. 3, pp. 421-436.

Efron, B. (1979), “Bootstrap Methods: Another Look at the Jackknife”. Ann. Statist., Vol. 7, pp. 1-26.

Gagné, M. and Deci, E. L. (2005), "Self-determination theory and work motivation". Journal of Organizational Behavior, Vol. 26, pp. 331-362.

Gardner, W. L., Avolio, B. J. and Walumbwa, F. O. (2005), “Authentic leadership development: Emergent themes and future directions", in W. L. Gardner, B. J. Avolio, 
and F. O. Walumbwa (Eds.), Authentic leadership theory and practice: Origins, effects, and development, Oxford, UK, pp. 387- 406.

Gatling, A., Hee, J., Kang, A. and Kim, J. S. (2016), "The effects of authentic leadership and organizational commitment on turnover intention", Leadership \& Organization Development Journal, Vol. 37 No. 2, pp. 181-199.

George, B., Sims, P., McLean, A.N. and Mayer, D. (2007), "Discovering your authentic leadership", Harvard Business Review, Vol. 85 No. 2, pp. 129-138.

George, W. (2003), Authentic leadership: Rediscovering the secrets to creating lasting value, Jossey-Bass, San Francisco.

Giallonardo, L.M., Wong, C.A. and Iwasiw, C.L. (2010), “Authentic leadership of preceptors: predictor of new graduate nurses' work engagement and job satisfaction", Journal of Nursing Management, Vol. 18 No. 8, pp. 993-1003.

Hair, J.F., Rolph., E.A., Ronald, L.T. and William, C.B. (1992), Multivariate Data Analysis with Readings, 3rd ed., Macmillan Publishing, New York, NY.

Harman, H. H. (1967), Modern Factor Analysis, University of Chicago Press, Chicago, IL.

Harter, S. (2002), "Authenticity”, in C. R. Snyder, \& S. Lopez (Eds.), Handbook of positive psychology, Oxford University Press, Oxford, UK, pp. 382-394.

Ilies, R., Morgeson, F. P. and Nahrgang, J. D. (2005), “Authentic leadership and eudaemonic well-being: Understanding leader-follower outcomes", The Leadership Quarterly, Vol. 16, pp. 373-94. 
Jaramillo, F., Mulki, J. P. and Marshall, G. W. (2005), "A meta-analysis of the relationship between organizational commitment and salesperson job performance: 25 years of research”, Journal of Business Research, Vol. 58, pp. 705-714.

Joo, B. and Nimon, K. (2014), “Transformational leadership and authentic leadership: A canonical correlational study", European Journal of Training and Development, Vol. 38, pp. 570-587.

Kernis, M. H. and Goldman, B. M. (2005), "From thought and experience to behavior and interpersonal relationships: A multicomponent conceptualization of authenticity", in A. Tesser, J. V. Wood and D. Stapel (Eds.), On bulding, defending and regulating the self: A psychological perspective, Psychology Press, New York, pp. 31-52.

Leroy, H., Palanski, M. and Simons, T. (2012), “Authentic Leadership and Behavioral Integrity as Drivers of Follower Commitment and Performance". Journal of Business Ethics, Vol. 107, pp. 255-264.

Luthans, F. and Avolio, B. (2003), "Authentic leadership development", in K. S. Cameron, J. E.Dutton and R. E. Quinn (Eds.), Positive organizational scholarship: Foundations of a new discipline, Berrett-Koehler, San Francisco, pp. 241-258.

Meyer, J. P. and Herscovitch, L. (2001), "Commitment in the workplace - Toward a general model”, Human Resource Management Review, Vol. 11 No. 3, pp. 299-326.

Meyer, J. P., Stanley, D. J., Herscovich, L. and Topolnytsky, L. (2002), “Affective, continuance, and normative commitment to the organization: A meta-analysis of antecedents, correlates, and consequences", Journal of Vocational Behavior, Vol. 61, pp. $20-52$. 
Meyer, J. P., Becker, T. E. and Vandenberghe, C. (2004), "Employee commitment and motivation: A conceptual analysis and integrative model", Journal of Applied Psychology, Vol. 89, pp. 991-1007.

Nazari K. and Emami M. (2012), "Leadership a critical review of the concept", Interdisciplinary Journal of Contemporary Research in Business, Vol. 3 No. 9, pp. 545553.

Podsakoff, P. M., MacKenzie, S. B., Lee, J. Y., and Podsakoff, N. P. (2003), “Common method biases in behavioral research: A critical review of the literature and recommended remedies", Journal of Applied Psychology, Vol. 88, pp. 879-903.

Preacher, K., Rucker, D. and Hayes, A. (2007), "Addressing moderated mediation hypotheses: Theory, methods, and prescriptions", Multivariate Behavioral Research, Vol. 42, pp. 185-227.

Rego, A. and Cunha, M. P. (2008a), "Perceptions of authentizotic climates and employee happiness: pathways to individual performance?", Journal of Business Research, Vol. 61 No. 7, pp. 739-752.

Rego, A. and Cunha, M. P. (2008b), “Organisational Citizenship Behaviours and Effectiveness: An Empirical Study in two Small Insurance Companies", Service Industries Journal, Vol. 28 No. 4, pp. 541-554.

Rego, A. and Souto S. (2004), “Comprometimento organizacional em organizações autentizióticas: Um estudo luso-brasileiro”, Revista de Administração de Empresas, Vol. 44 No. 3, pp. 30-43. 
Rego, A., Sousa, F., Cunha, M. P., Correia, A. and Saur-Amaral, I. (2007), "Leader selfreported emotional intelligence and perceived employee creativity: An exploratory study", Creativity and Innovation Management, Vol. 16 No. 3, pp. 250-263.

Rego, A. Sousa, F., Marques, S., and Cunha, M. P. C. (2012), “Authentic leadership promoting employees' psychological capital and creativity", Journal of Business Research, Vol. 65 No. 3, pp. 429-437.

Rego, A., Vitória, A., Magalhães, A., Ribeiro, N. and Cunha, M. P. (2013), “Are authentic leaders associated with more virtuous, committed and potent teams?" The Leadership Quartetly, Vol. 24, pp. 61-79.

Riketta, M. (2002), “Attitudinal organizational commitment and job performance: a metaanalysis", Journal of Organizational Behavior, Vol. 23 No. 3, pp. 257-266.

Shahid N. K. (2010), "Impact of Authentic Leaders on Organization Performance", International Journal of Business and Management, Vol. 5 No. 12, pp. 167-172.

Shamir, B. and Eilam, G. (2005), ““What's your story?”: A life-stories approach to authentic leadership development”, Leadership Quarterly, Vol. 16, pp. 395-417.

Shrout, P. E., and Bolger, N. (2002), "Mediation in Experimental and Nonexperimental Studies: New Procedures and Recommendations", Psychological Methods, Vol. 7 No. 4, pp. $422-445$.

Semedo, S., Coelho, A. and Ribeiro, N. (2016), "Effects of authentic leadership, affective commitment and job resourcefulness on employees' creativity and individual performance", Leadership \& Organization Development Journal, Vol. 37 No. 8, pp. 1038-1055. 
Sobel, M. E. (1982), “Asymptotic intervals for indirect effects in structural equations models", in Leinhart, S. (Ed.), Sociological Methodology, Jossey-Bass, San Francisco, pp. 290-312.

Simons, T. L. (1999), "Behavioral integrity as a critical ingredient for transformational leadership", Journal of Organizational Change Management, Vol. 12, pp. 89-104.

Staples, S. D., Hulland, J. S. and Higgins, C. A. (1999), “A self-efficacy theory explanation of the management of remote workers in virtual organization", Organization Science, Vol. 10 No. 6, pp. 758-776.

Steffens, N.K., Haslam, S.A., Kerschreiter, R., Schuh, S.C. and van Dick, R. (2014), “Leaders enhance group members' work engagement and reduce their burnout by crafting social identity", Zeitschrift für Personalforschung, Vol. 28 No. 1/2, pp. 173-194.

Trivellas, P. (2011), "Work motivation and job performance of frontline employees: the mediating role of organizational commitment", in 2011 IEEE International Conference on Industrial Engineering and Engineering Management (IEEM), proceedings of IEEE, pp. 1878-1882.

Vandenberghe, C., Bentein, K., and Stinglhamber, F. (2004), “Affective commitment to the organization, supervisor, and work group: Antecedents and outcomes", Journal of Vocational Behavior, Vol. 64, pp. 47-71.

Vandenabeele, W. (2009), "The mediating effect of job satisfaction and organizational commitment on self-reported performance: more robust evidence of the PSM performance relationship", International Review of Administrative Sciences, Vol. 75 No. 1, pp. 11- 34 . 
Walumbwa, F. O., Luthans, F., Avey, J. B. and Oke, A. (2011), “Authentically leading groups: The mediating role of collective psychological capital and trust", Journal of Organizational Behavior, Vol. 32, pp. 4-24.

Walumbwa F. O., Avolio, B. J. Gardner, W. L., Wernsing, T. S. and Peterson, S. J. (2008), "Authentic Leadership: Development and Validation of a Theory-Based Measure", Journal of Management, Vol. 34 No. 1, pp. 89-126.

Walumbwa, F. O.,Wang, P.,Wang, H., Schaubroeck, J., and Avolio, B. J. (2010), "Psychological processes linking authentic leadership to follower behaviors", Leadership Quarterly, Vol. 21 No. 5, pp. 901-914.

Yammarino, F. J., Dionne, S. D., Schriesheim, C. A., and Dansereau, F. (2008), "Authentic leadership and positive organizational behavior: A meso, multi-level perspective", Leadership Quarterly, Vol. 19 No. 6, pp. 693-707.

Youssef, D.A. (2000), “Organizational commitment: a mediator of the relationships of leadership behavior with job satisfaction and performance in a non-Western country", Journal of Managerial Psychology, Vol. 15, pp. 6-24. 
Table 1 - Correlation Matrix

\begin{tabular}{lccccccc}
\hline & Mean & S.D. Gender & Age & AL & AC & IP \\
Gender & - & - & - & & & & \\
Age & - & - & .099 & - & & & \\
Authentic Leadership (AL) & 2.90 & - & -.041 & -.123 & $.96^{(a)}$ & & \\
Affective Commitment (AC) & 6.46 & - & .014 & .049 & $.223^{* *}$ & $.85^{(a)}$ & \\
Individual Performance (IP) & 5.78 & - & -.002 & $.170^{*}$ & $.195^{* *}$ & $.367^{* *}$ & $.63^{(a)}$ \\
\hline
\end{tabular}

*Correlation is significant at $p ., 05$;

**Correlation is significant at $p ., 01$;

${ }^{a)}$ Cronbach Alpha

Table 2 - Regression step between the mediator and the predictor variable

\begin{tabular}{|c|c|c|c|c|c|c|}
\hline \multicolumn{2}{|c|}{ Model } & \multicolumn{2}{|c|}{$\begin{array}{l}\text { Unstandardized } \\
\text { Coefficients }\end{array}$} & $\begin{array}{c}\text { Standardized } \\
\text { Coefficients } \\
\text { Beta }\end{array}$ & $t$ & Sig. \\
\hline 1 & Gender & .012 & .094 & .009 & .137 & .892 \\
\hline \multirow{4}{*}{2} & Age & .004 & .006 & .048 & .686 & .494 \\
\hline & Gender & .022 & .089 & .016 & .241 & .809 \\
\hline & Age & .006 & .005 & .076 & 1.108 & .296 \\
\hline & Authentic Leadership & .192 & .056 & .233 & 3.424 & .001 \\
\hline
\end{tabular}

a. Dependant Variable: Affective Commitment

Note: bootstrapping performed at 1000 samples

Table 3 - Regression step between the predictor and the dependant variable, controlling the mediator ( $2^{\text {nd }}$ and $3^{\text {rd }}$ Step)

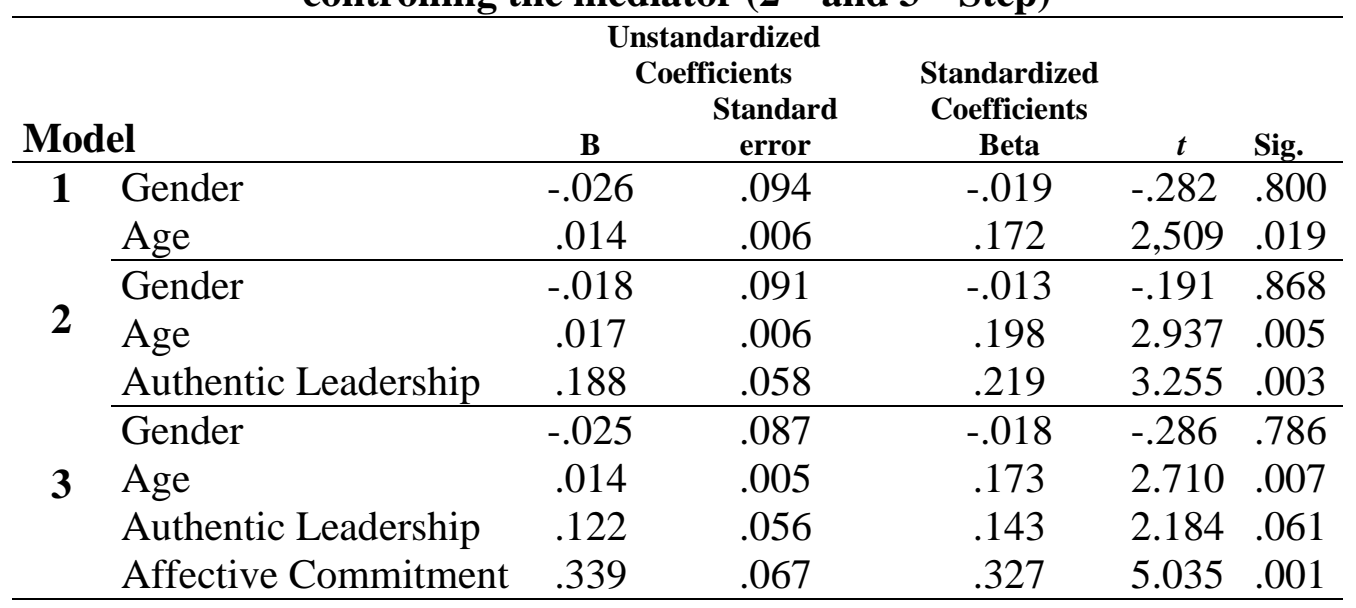

a. Dependant Variable: Individual Performance

Note: bootstrapping performed at 1000 samples 
Figure 1 - Simplified Model of Analysis with results

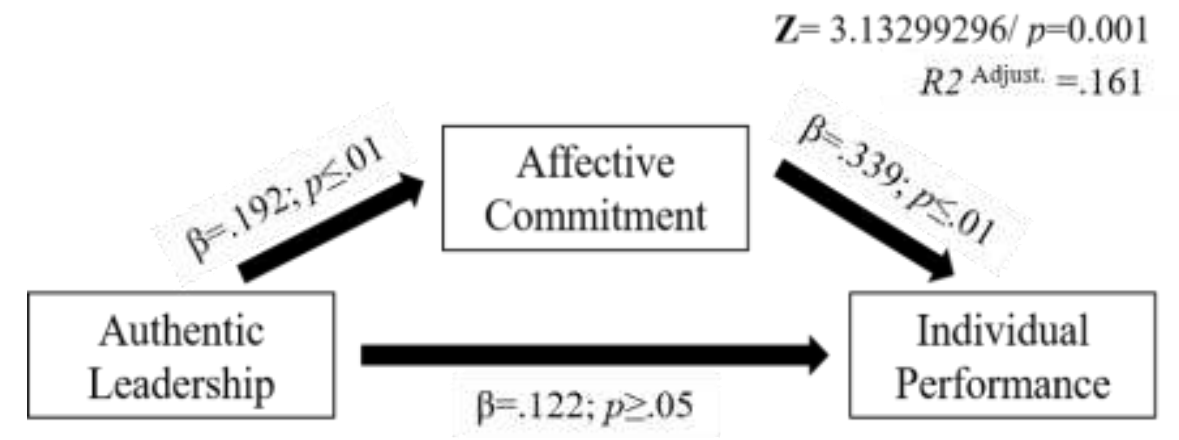

